\title{
A novel frameshift mutation in the PITX2 gene in a family with Axenfeld-Rieger syndrome using targeted exome sequencing
}

Lusi Zhang ${ }^{1,2+}$, Yingqian Peng ${ }^{1,2 \dagger}$, Pingbo Ouyang ${ }^{1,2}$, Youling Liang ${ }^{1,2}$, Huilan Zeng ${ }^{1,2}$, Nuo Wang ${ }^{1,2}$, Xuanchu Duan ${ }^{1,2}$ and Jingming Shi ${ }^{1,2^{*}}$ (D)

\begin{abstract}
Background: Axenfeld-Rieger syndrome (ARS) is an autosomal dominant genetic disorder that is characterized by specific abnormalities of the anterior segment of the eye. Heterozygous mutations in two developmental transcription factor genes PITX2 and FOXC1 have been identified within ARS patients, accounting for 40 to $70 \%$ of cases. Our purpose is to describe clinical and genetic findings in a Chinese family with ARS.

Methods: An ARS family with three affected members was recruited. The patients underwent a series of complete ophthalmologic examinations, general physical examination and dental radiography. DNA samples of proband II-1 were used for targeted exome sequencing of the FOXC1 and PITX2 genes. Sanger sequencing was used to validate the variation in PITX2. Quantitative real-time PCR was carried out to detect the expression of PITX2 in patients and normal controls.

Results: All affected members showed iris atrophy, corectopia, shallow anterior chamber, complete or partial angle closure, and advanced glaucoma. In addition, they revealed systemic anomalies, including microdontia, hypodontia, and redundant periumbilical skin. A novel heterozygous frameshift variation, c.515delA, in PITX2 was found in the proband, which might lead to a truncated PITX2 protein ( $p . G \ln 172 \mathrm{Argfs} X 36)$. Sanger sequencing validated that the variation completely cosegregated with the ARS phenotype among this family, but was absent in 100 unrelated controls. Quantitative real-time PCR analysis revealed that the mRNA expression of PITX2 was significantly decreased in patients compared with that in unrelated normal controls.
\end{abstract}

Conclusions: PITX2 c.515delA (p.Gln172ArgfsX36) was the genetic etiology of our pedigree. The mutation led to decreased PITX2 gene expression and a truncated mRNA transcript.

Keywords: Axenfeld-Rieger syndrome, PITX2, Targeted exome sequencing, Frameshift variation

\section{Background}

Axenfeld-Rieger syndrome (ARS) is an autosomaldominant genetic disorder that is characterized by specific abnormalities of the anterior segment of the eye [1]. The diagnosis of ARS refers to a serious of ocular phenotypes,

\footnotetext{
* Correspondence: sjm93cn@csu.edu.cn

${ }^{+}$Lusi Zhang and Yingqian Peng contributed equally to this work.

'Department of Ophthalmology, The Second Xiangya Hospital, Central South University, 139 Renmin Middle Road, Changsha 410011, Hunan, People's Republic of China

${ }^{2}$ Hunan Clinical Research Center of Ophthalmic Disease, Changsha, Hunan, People's Republic of China
}

including anomalies of the anterior chamber angle and aqueous drainage structures, iris hypoplasia, corectopia (eccentric pupil), polycoria (iris tears), and iridocorneal tissue adhesions traversing the anterior chamber [2].Because of these changes in the trabecular meshwork and iris, patients are at high risk for raised intraocular pressure, and an increased incidence of glaucoma affecting approximately $50 \%$ of cases has been reported [3]. Systemic disorders can also occur with these eye anomalies, which include dental hypoplasia, facial dysmorphism, abnormality of the cardiovascular outflow 
tract, failure of periumbilical skin involution, and maxillary hypoplasia [4, 5]. However, these systemic disorders often reveal incomplete penetrance and variable expressivity.

To date, heterozygous mutations in two developmental transcription factor genes PITX2 and FOXC1 have been identified within ARS patients, accounting for 40 to $70 \%$ of cases $[6,7]$. Additionally, two other loci on 13q14 and $16 \mathrm{q} 24$ have been suggested. However, the underlying genes at these loci have not been identified $[8,9]$. For significant clinical and genetic heterogeneity, affected patients exhibit various ocular and systemic abnormities, which often complicates diagnosis. In this sense, genetic analysis combined with clinical diagnosis is becoming a promising way to clarify diagnostic classification.

In recent years, exome sequencing has provided a powerful tool to identify causative genes in Mendelian and complex disorders $[10,11]$. In the present study we aimed to identify the genetic etiology underlying a Chinese pedigree with ARS through targeted exome sequencing.

\section{Methods}

\section{Subjects and clinical evaluation}

A Chinese Han family with three affected individuals was included in the study (Fig. 1a). A total of 100 normal controls were recruited mainly from volunteers. The study adhered to the principles of the Declaration of Helsinki, and the clinic protocols were approved by the Second Xiangya Hospital Institutional Review Board. After obtaining written informed consent from patients and the parent, peripheral blood samples were obtained from the family members and the normal volunteers, and DNA was extracted using a standard phenol chloroform method.

All affected members underwent standard ophthalmic examinations including evaluation of best-corrected visual acuity (BCVA), Goldman applanation tonometry, slit-lamp biomicroscopic examination and fundus examination via direct and indirect ophthalmoscopy. Other clinic characterizations of affected individuals included funduscopy (nonmydriatic retinal camera, TRC-NW300, Topcan, Itabashi-ku, Tokyo, Japan), anterior segment photography (SL-D4, Topcan, Itabashi-ku, Tokyo, Japan) and ultrasound biomicroscopy (UBM) as well as assessment of visual field defects performed with a Humphrey vsual field analyzer (Carl Zeiss Humphrey Systems, Dublin, CA, USA). All participants were examined by a general physician and a dentist for the presence or absence of systemic and dental abnormalities. All patients also underwent general physical examination and dental panoramic radiography. The diagnosis of ARS was based upon medical history, clinical features and heredity of the disease.

\section{Targeted exome sequencing}

Genomic DNA was extracted according to the standard phenol-chloroform method. A DNA sample of proband II-1 was used for targeted exome sequencing of the FOXC1 and PITX2 genes. Library construction was performed by the NimbleGen SeqCap EZ System (Roche NimbleGen, Madison, Wisconsin, USA) according to the manufacturer's instructions. 90 cycle paired-end sequencing was performed on Illumina HiSeq2500 Analyzers (Illumina, San Diego, California, USA) following the manufacturer's instructions. Illumina Pipeline software (version 1.3.4) was used to perform base-calling and to calculate the quality values for every base.

Reads were aligned to the human reference genome National Center for Biotechnology Information (NCBI) GRCh37 using Burrows-Wheeler Aligner (BWA). Single nucleotide variations (SNVs) and insertions and deletions (indels) identification was performed by SOAPsnp and samtools. SNVs and indels with read depth $\geq 8 \times$ and quality $\geq 30$ were reserved for subsequent analysis. Based on the dbSNP database and the 1000 genomes annotation, the polymorphic SNVs were excluded. SNVs and indels affecting coding sequence were annotated using Annotate Variation (ANNOVAR) software.

\section{Sanger sequencing of implicated genes}

PCR amplification and Sanger sequencing of the amplicons were used to validate the pathogenic mutation in PITX2 (NM_000325) identified via exome sequencing. The primer sequences are shown as follows: forward primer, 5'cactgtggcatctgtttgct- 3 ', and reverse primer, $5^{\prime}$-ACGGGC TACTCAGGTTGTTC-3'. PCR was performed in a 10- $\mu \mathrm{l}$ reaction mixture using $2 \times \mathrm{TaKaRa}^{\mathrm{Taq}}{ }^{\mathrm{Tm}}$ HS Perfect Mix (Takara Biotechnology, Dalian, China). The amplification conditions consisted of an initial denaturation step at $94{ }^{\circ} \mathrm{C}$ for $30 \mathrm{~s}$, followed by 33 cycles of denaturation at $94^{\circ} \mathrm{C}$ for $5 \mathrm{~s}$, annealing at $60^{\circ} \mathrm{C}$ for $20 \mathrm{~s}$, and extension at $72{ }^{\circ} \mathrm{C}$ for $20 \mathrm{~s}$. Final extension was performed at $72^{\circ} \mathrm{C}$ for $7 \mathrm{~min}$.

\section{RNA expression analysis by real-time quantitative PCR} Total RNA was extracted from peripheral blood lymphocytes of three patients as well as three unrelated normal controls using TRIzol reagent (Life Technologies, NY, USA). cDNA was synthesized from $0.1 \mu \mathrm{g}$ of total RNA using the RevertAid First Strand cDNA Synthesis Kit (Thermo Scientific, Inc., Waltham, MA, USA) and oligo (dT) primers. Quantitative real-time PCR was carried out with an Applied Biosystems ${ }^{\circ}$ StepOne ${ }^{\text {Tw }}$ Plus RealTime PCR System (Thermo Scientific, Inc., Waltham, MA, USA) using Maxima SYBR Green qPCR Master Mixes (Thermo Scientific, Inc., Waltham, MA, USA). Data were normalized to $\beta$-actin and analyzed by the comparative CT method. Specific primers for each gene were as follows: forward primer PITX2-1-F, 5'-TACC 

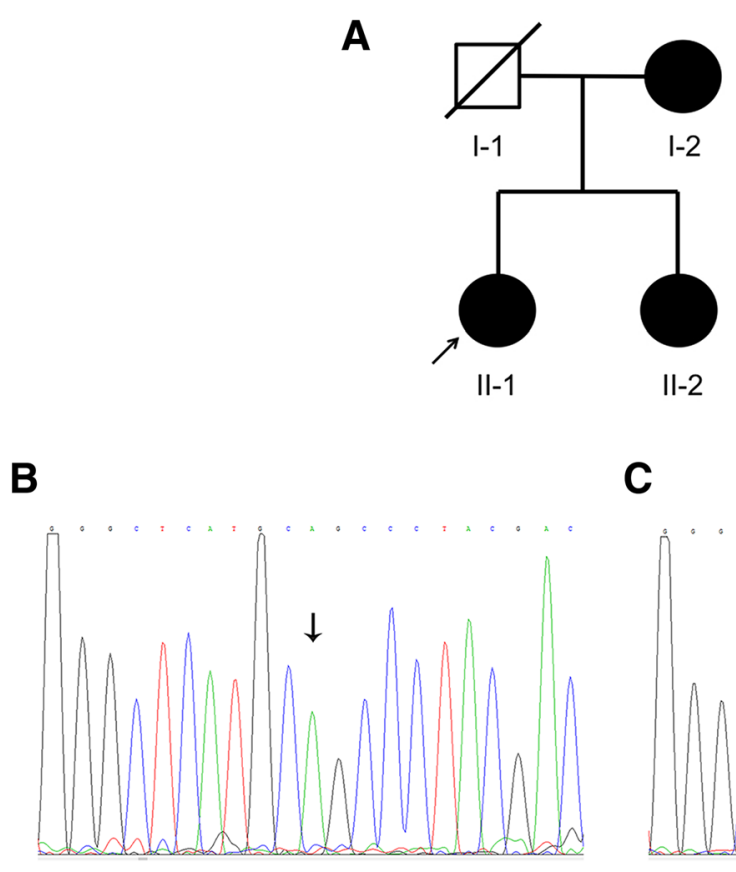

D

C

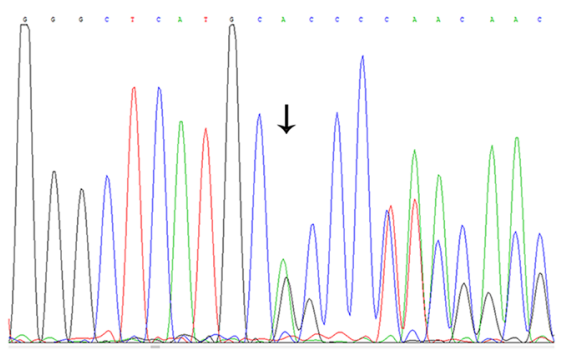

$\mathbf{E}$
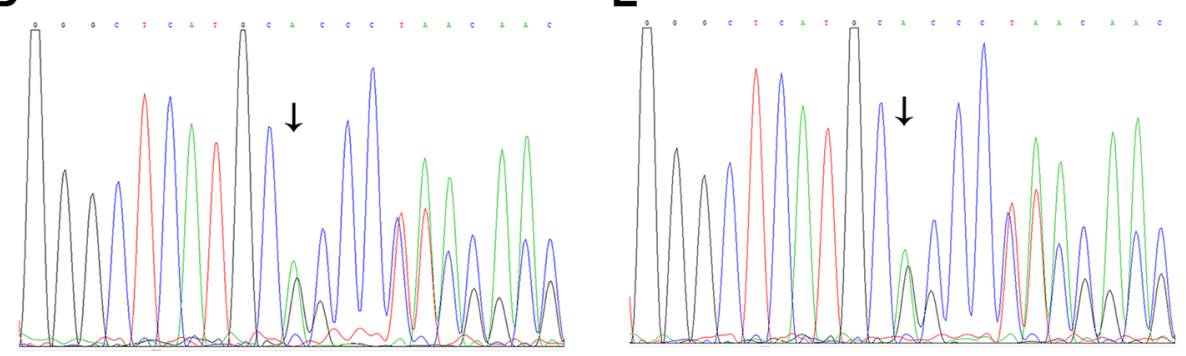

Fig. 1 Pedigree and sequence analysis of the PITX2 gene in a Chinese family with Axenfeld-Rieger syndrome. a Roman numerals refer to generations, and individuals within a generation are numbered from left to right. Proband II-1 is noted with an arrow; the filled symbol refer to the patients; and the slash refers to the dead individual. b-e, the DNA sequence of the CHM c.280delA mutation in the normal control (b) and the patients (c, I-2; d, II-1; and $\mathbf{e}, 1 \mid-2)$. The arrow indicates the mutated base

TGTCCCTGTCACTCTTGA-3', and reverse primer PITX2-1-R, 5'-AAGAACCCCTCCAATAAGGAAA-3' for PITX2 (before c.515); forward primer PITX2-2-F, 5'CCTTACATCCGCCTCCCTAT-3' and reverse primer PITX2-2-R, 5' -GTGGGGAAAACATGCTCTGT-3' for PITX2 (after c.515); forward primer, 5'-CACGATGGAGGGGCCGGACTCATC $-3^{\prime}$, and reverse primer, 5'-TAAAGACCTCTATGCCAACACAGT-3' for $\beta$-actin. Statistical analyses were performed using Prism 5 software (GraphPad Software, Inc., La Jolla, CA, USA). Two-tailed Student's $t$ test was used to determine the significance of differences between two groups. The data are presented as the mean \pm SEM.

\section{Results}

\section{Clinical characterization}

This family had three affected members: the proband, her mother, and her younger sister (Fig. 1a). Table 1 and
Table 2 summarize the clinical characteristics of the ocular and systemic features of the three patients in this family. Proband II-1 was a 19-year-old female referred to our outpatient clinics because of uncontrolled intraocular pressure (IOP) in both eyes under medical therapy and was diagnosed with iridocorneal endothelial (ICE) syndrome by other hospitals. Case 2 (I-2), a 42-year-old woman, was the mother of the proband who had a trabeculectomy in her left eye 14 years ago because of uncontrolled high IOP $(\geq 60 \mathrm{mmHg})$. Her right eye was blind since childhood, and she never received treatment. Ocular examinations showed adherent leukoma of her right eye. Case 3 (II-2) was the 14-year-old sister of the proband who was referred to our clinic because of low visual acuity in both eyes since childhood.

All three cases showed that the abnormality of the anterior segment of their eyes included different degrees of pupil deformation, iris hypoplasia and iris atrophy in 
Table 1 Summary of clinical features of affected family members with Axenfeld-Rieger syndrome

\begin{tabular}{|c|c|c|c|c|}
\hline $\begin{array}{l}\text { Affected family } \\
\text { members }\end{array}$ & & $1-2$ & $\|-1$ & $\| \mathrm{H}-2$ \\
\hline Currente age (years old) & & 42 & 20 & 14 \\
\hline Onset age (years old) & & 28 & 18 & 11 \\
\hline Gender & & $\mathrm{F}$ & $\mathrm{F}$ & $\mathrm{F}$ \\
\hline \multicolumn{5}{|l|}{ Clinical Features } \\
\hline \multirow[t]{7}{*}{ Eye } & Iris dysplasia (goniodysgenesis) & + & + & + \\
\hline & Iris hypoplasia & + & + & + \\
\hline & Pupil deformation & + & + & + \\
\hline & Secondary Glaucoma & + & + & + \\
\hline & Polycoria & + & + & + \\
\hline & Corectopia (displaced pupils) & + & + & + \\
\hline & Shallow anterior chamber & + & + & + \\
\hline Nose & Broad nasal bridge & $+/-$ & + & + \\
\hline Teeth & Microdontia & + & + & + \\
\hline Abdomen & $\begin{array}{l}\text { Umbilical defect (redundant } \\
\text { periumbilical skin) }\end{array}$ & + & + & + \\
\hline
\end{tabular}

F-Female

both eyes (except the mother since her right eye showed adherent leukoma). However, when we compared the degree of these symptoms, clearly II-2 was the most severe, followed by her elder sister (proband) with moderate anterior segment abnormality, and I-1 was shown to be the mildest compared to her daughters (Fig. 2 a, b and c). Slit-lamp examination revealed a shallow anterior chamber of both eyes in all cases, which was confirmed by UBM (Fig. $2 \mathrm{~d}$, e and f). Apparent microdontia, broad nasal bridges and redundant periumbilical skin were observed in all patients (microdontia of the mother existed before the dental implant was performed 20 years ago) (Fig. 3).

The results of other ocular examinations, including BCVA, IOP, specular microscope, central corneal thickness $(\mathrm{CCT})$, horizontal corneal diameter, Humphrey visual field analyzer (HFA) and the cup-to-disc (CD) ratio of each patients, are shown in Table 2 in details. After trabeculectomy for the left eye of the proband and regular medical therapy with Lumigan for her right eye, her IOP was controlled in an ideal range, which was $\leq 21 \mathrm{mmHg}$ for the right eye and between 13 and $15 \mathrm{mmHg}$ for the left eye. The BCVA of her left eye increased to 20/25.

When we compared the onset age (Table 1), II-2 was the earliest, with an age of 11 years, immediately followed by her elder sister (proband) with an age of 18 years. The onset age of I-1 was 29 years, which was considered to be the oldest age.

\section{Targeted exome sequencing and sanger validation}

We selected proband II-1 for targeted exome sequencing analysis, which was designed to capture a 2637-bp DNA region in the two ARS candidate genes PITX2 and FOXC1 (Table 3). After sequencing, 82.03\% of the qualified bases were mapped to the targeted sequence, with a mean read depth of approximately 151.61-fold, and the exon coverage rate was 96\% (Table 3). After alignment and variation calling, 5 variations in the PITX2 and FOXC1 genes were identified, including $4 \mathrm{SNVs}$ and 1 indel (data not shown). However, only the novel heterozygous frameshift variation c.515delA in PITX2 was found in both the dbSNP database and 1000 genomes databases, which might lead to a truncated PITX2 protein (p.E172RfsX36).

By Sanger sequencing we validated that proband II-1 carries the heterozygous variation c.515delA in PITX2 (Fig. 1d). Then, the exon was screened in other family members of the pedigree (I-2 and II-2), both of whom were patients, and they also carried heterozygous c.515delA variation (Fig. 1c, e). The variation completely cosegregated with the ARS phenotype among this family and was absent in the 100 unrelated controls (Fig. 1b). Taken together, our results indicated that the novel mutation c.515delA in PITX2 is the disease-causing mutation in this ARS pedigree.

Table 2 Ocular examinations of affected family members with Axenfeld-Rieger Syndrome

\begin{tabular}{|c|c|c|c|c|c|c|}
\hline \multirow[t]{2}{*}{ Ocular examinations } & \multicolumn{2}{|l|}{$1-2$} & \multicolumn{2}{|l|}{$\|-1$} & \multicolumn{2}{|l|}{$\|-2$} \\
\hline & $\mathrm{OD}$ & OS & $\mathrm{OD}$ & OS & $\mathrm{OD}$ & OS \\
\hline BCVA & NLP & $20 / 200$ & $20 / 20$ & $20 / 33$ & $20 / 50$ & $20 / 33$ \\
\hline IOP (Goldman tonometry, mmHg) & N/A & $21^{a}$ & 25 & 40 & 34 & 34 \\
\hline $\mathrm{CCT}(\mu \mathrm{m})$ & N/A & 618 & 562 & 579 & 560 & 564 \\
\hline$C / D$ & N/A & 0.9 & 0.3 & 1.0 & 0.5 & 0.5 \\
\hline FHA: MD (dB) & $x$ & $x$ & -0.69 & -4.8 & -11.74 & $x$ \\
\hline Horizontal corneal diameter (mm) & 7.5 & 9 & 9.5 & 9.5 & b & b \\
\hline Specular microscope (cells/m²) & b & b & 1626 & 1636 & b & b \\
\hline
\end{tabular}

C/D cup-to-disc ratio, FHA Humphrey Visual Field Analyzer, MD Mean Deviation, NLP No light perception; N/A: the patient can not finish the examination because of adherent leukoma; $x$ : the patient can not finish the examination because of low vision; ${ }^{a} \mathrm{OOP}$ after trabecylectomy; ${ }^{\mathrm{b}}$ the patient refuses to do the examination; IOP reference range: $\leq 21 \mathrm{mmHg}$ 


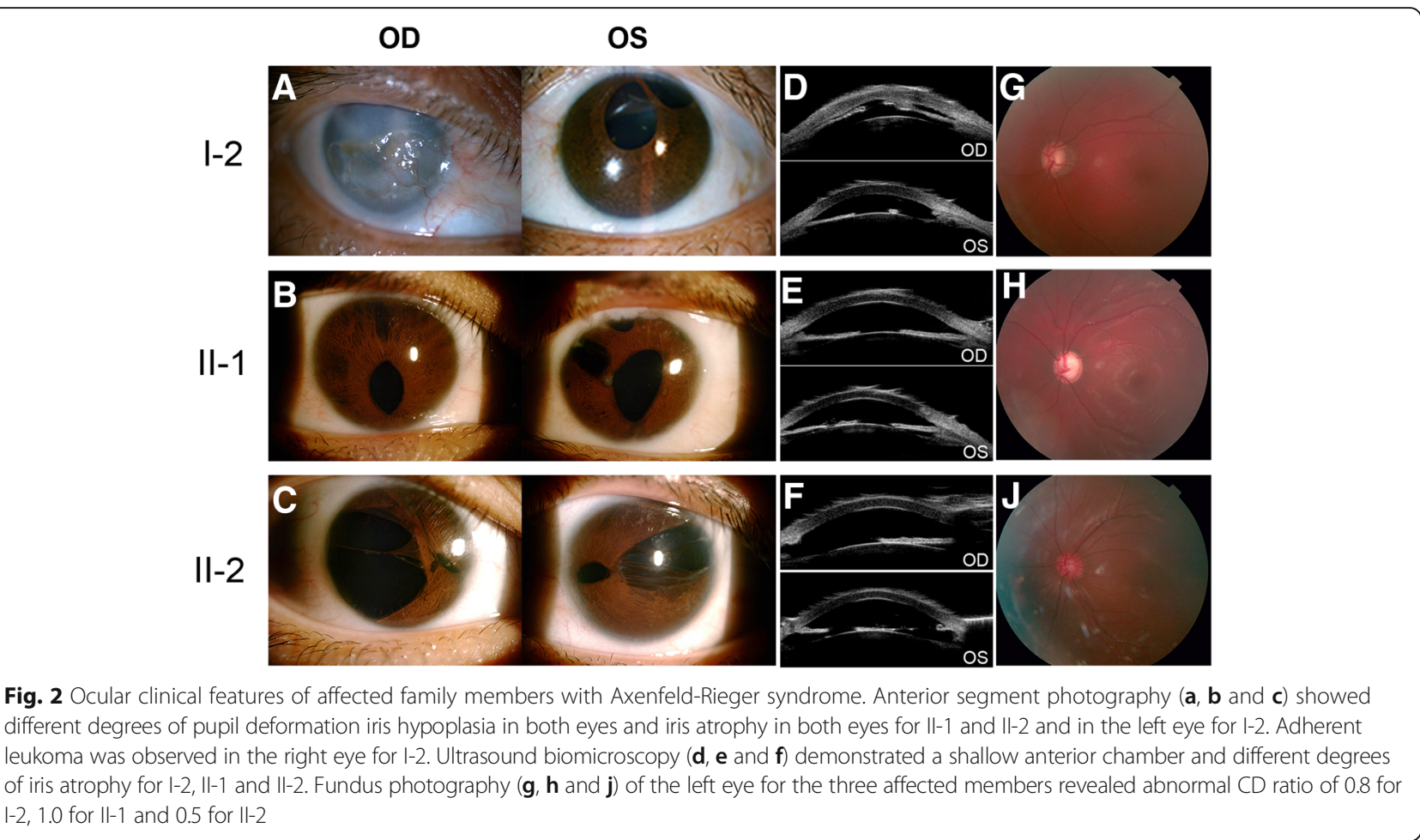

\section{PITX2 expression analysis by real-time quantitative PCR}

Because the frameshift mutation usually causes declined gene expression, we examined the expression of PITX2 in peripheral blood lymphocytes of our three patients and three unrelated normal controls through real-time quantitative PCR. Two pairs of primers were designed according to the PITX2 mRNA sequences before and after the mutant site c.515 to detect the mRNA expression of the pitx2 mRNA including truncated and fulllength transcripts, or only full-length transcripts. As shown in Fig. 4, our patients revealed significantly decreased PITX2 expression $(29.19 \pm 4.43 \%, p=0.0008$ for pitx2-primer 1 detection; $6.75 \pm 1.73 \%, p=0.0003$ for pitx2-primer 2) compared with controls, indicating that the mutant would harm the expression of the PITX2 gene. Moreover, full-length PITX2 mRNA expression in patients (pitx2-primer 2 amplicon in patients) is much lower $(p=0.0091)$ than that of both truncated and fulllength forms (primer 1 amplicon in patients) in patients, which means that the mutant DNA cannot normally express a full-length mRNA version but only a decreased truncated mRNA transcript. Taken together, these results suggested that PITX2 c.515delA is a dominant negative mutation that both impaired the expression of PITX2 and resulted in a truncated mRNA transcript.

\section{Discussion}

In our present study, we identified a PITX2 heterozygous frameshift mutation (c.515delA, p.E172RfsX36) that cosegregated with the ARS phenotype in our pedigree. Our real-time quantitative PCR results indicated a dominant negative effect of our mutation and decreased PITX2 mRNA expression, which would be a pathogenic mechanism of our mutation.

ARS exhibits considerable phenotypic heterogeneity between affected individuals particularly with regard to the ocular anterior segment abnormalities, with or without other syndromic abnormalities. This can occur between different affected members within a single pedigree or between families carrying different mutations in the same gene [12]. In our pedigree, all three patients showed similar phenotypes, including anterior segment abnormality shown in Table 1, high IOP, increased C/D (cup-to-disc), microdontia, broad nasal bridge and redundant periumbilical skin. However, the level of severity for those symptoms and clinical characteristics differed from each other. Patient II-2 (the younger sister of the proband) was considered the most severe in the pedigree. The proband was more severe than their mother as well. The onset age of patient II-2 is younger than that of the proband. Thus, the mutation is at full penetrance, but disease severity shows variability.

PITX2 encodes a $33 \mathrm{kDa}$ bicoid-related homeodomain transcription factor, which belongs to the RIEG/PITX homeobox family. The protein contains a 60-amino-acid homeodomain at the $\mathrm{N}$ terminus and a 14-amino-acid $\mathrm{C}$-terminal OAR domain, which mediate protein-protein 

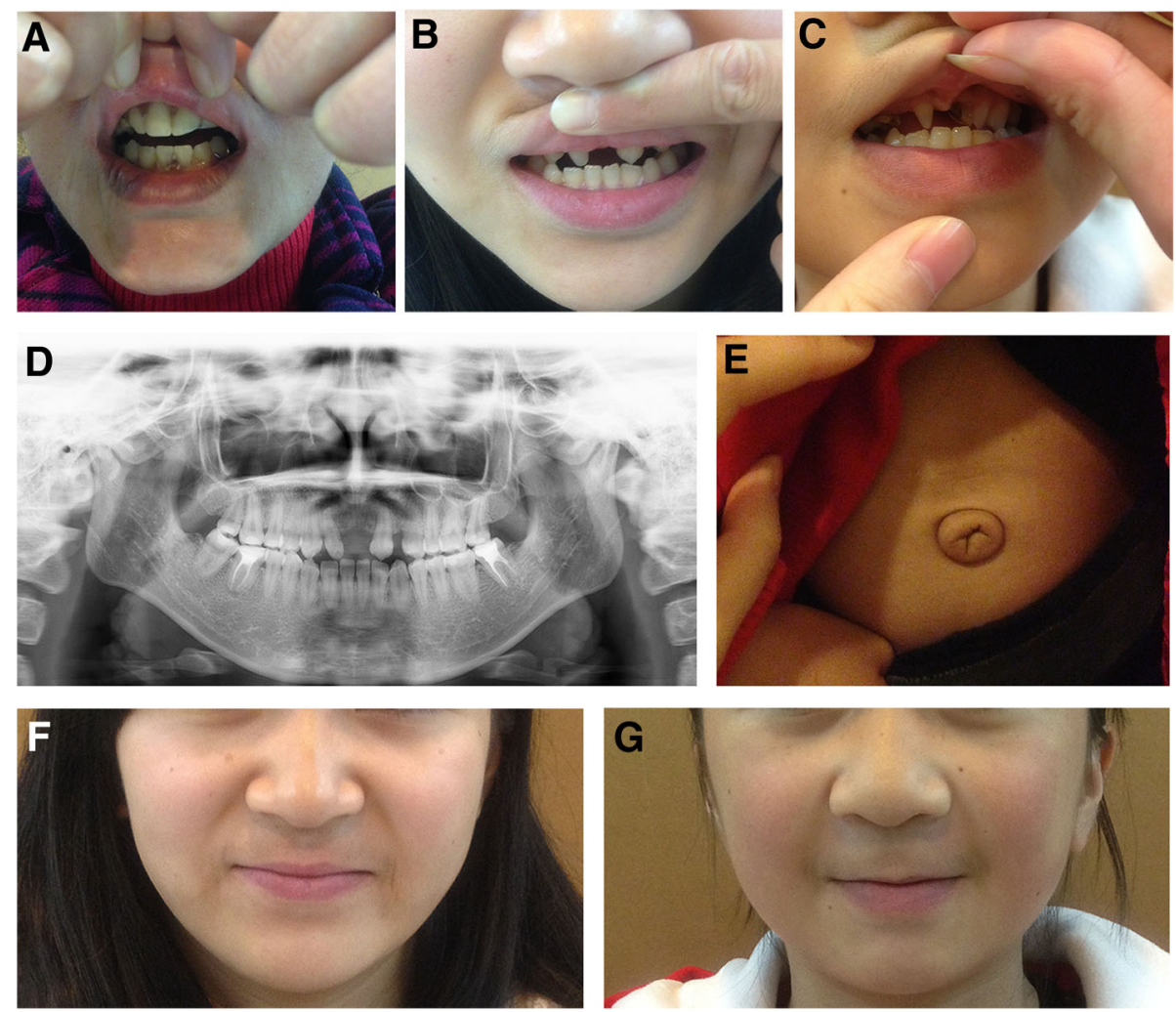

Fig. 3 Systemic clinic features of affected family members with Axenfeld-Rieger syndrome. No microdontia was observed for $1-2$ because of a dental implant (a). Apparent microdontia for II-1 and II-2 (b and c). Dental panoramic radiography for II-1 (d), and II-2 had similar dental panoramic radiography. Umbilical defect (redundant periumbilical skin) for II-2 (e). All three patients exhibited the same sign when they underwent general physical examination. Broad nasal bridge of II-1 and II-2 (f and $\mathbf{g}$ )

interaction and self-inhibitory interaction with the $\mathrm{N}$ terminus [13]. The PITX2 protein participates in regulating the development of ocular anterior segment [14], as well as several nonocular tissues including branchial arches [15], heart [16], and the pituitary [17]. Mutations in PITX2 have been associated with ARS and other anterior segment malformations, including Peter's-like anomaly, iridogoniodysgeniesis syndrome (IGDS) and iris hypoplasia (IH) [18-20]. The novel frameshift mutation c.515delA (p.E172RfsX36) leads to the adenine deletion in c.515 of PITX2, causing the glutamic acid in amino acid 172 replaced by arginin in the mutant transcript (Fig. 3b), which is predicted to create a shift in the reading frame and introduce a stop codon at position 208. The mutant amino acids are located in the highly conserved C-terminal domain of PITX2, which includes a transcriptional stimulatory domain in residues $160-232$ and the transcriptional inhibitory OAR domain in residues 233-271 [21]. Moreover, the C-terminal region of PITX2 was suggested to facilitate intramolecular interactions that modulate DNA binding and transactivation [22]. Altogether, the protein-truncating mutation is predicted to disrupt C-terminal domain mediated protein interaction as well as its transcriptional regulation function. In addition, this mutation results in a significant and extreme decrease in the expression level of fulllength PITX2 mRNA in affected individuals, which indicated that the mutant protein acts in a dominant negative manner, other than the haploinsufficient effect, to suppress wildtype PITX2 expression. Because stringent control of PITX2 is required for normal ocular development and function, the alteration in the level of functional protein is the cause of the ARS phenotype in our pedigree.

Table 3 Summary of the targeted exome sequencing results

\begin{tabular}{|c|c|c|c|c|c|c|}
\hline Sample & Targeted Gene & Targeted region (bp) & Targeted region coverage (\%) & Targeted exon coverage (\%) & Mean depth $(x)$ & Mean depth $>30 \times(\%)$ \\
\hline$\|-1$ & FOXC1, PITX2 & 2637 & 82.03 & 96 & 151.61 & 63.48 \\
\hline
\end{tabular}




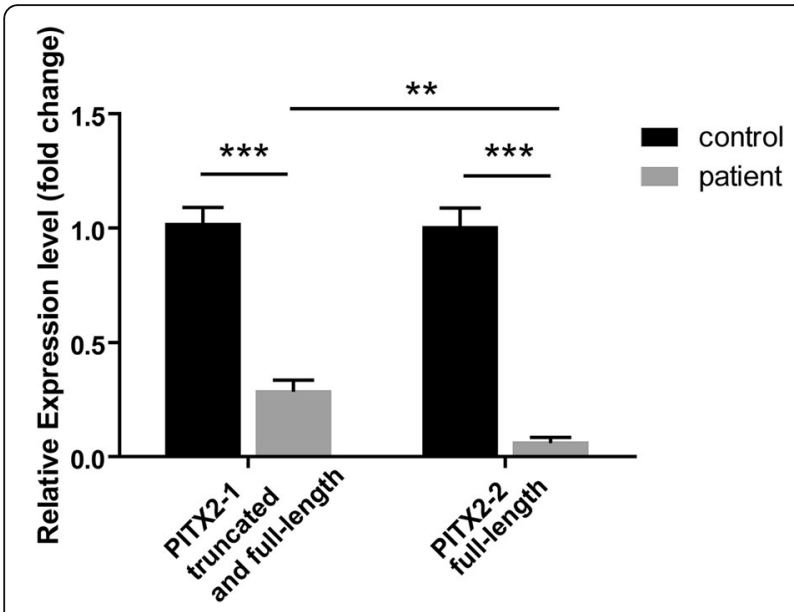

Fig. 4 The mRNA expression of PITX2 in lymphocytes of the affected individuals and the controls. The mean expression $( \pm$ SEM) of PITX2 mRNA in affected individuals $(n=3)$ and controls $(n=3)$ was measured by quantitative real-time PCR by primers before (PITX2-1) and after (PITX2-2) the mutant site. PITX2-1 columns represent both truncated and full-length pitx2 transcripts, while PITX2-2 columns indicate the full-length PITX2 mRNA. **, $p<0.05 ;{ }^{* * *}, p<0.01$

\section{Conclusion}

Our study described a novel PITX2 frameshift mutation in the ARS family by combining exome sequencing with segregation analysis and expression analysis. A dominant negative effect leading to decreased protein expression as well as a truncated transcript caused by the mutation is the etiology of a Chinese family with Axenfeld-Rieger syndrome.

\section{Abbreviations}

ARS: Axenfeld-Rieger syndrome; BCVA: Best-corrected visual acuity; C/D: Cupto-disc; CCT: Central corneal thickness; ICE: Iridocorneal endothelial; IOP: Intraocular pressure; NCBI: National Center for Biotechnology Information; SNVs: Single nucleotide variations; UBM: Ultrasound biomicroscopy

\section{Acknowledgments}

We wish to thank all of the patients, their family members, and healthy individuals for their voluntary participation and cooperation in this study.

\section{Authors' contributions}

$\mathrm{LZ}$ and PO carried out the genetic studies, and YP and $\mathrm{HZ}$ participated in the sequence alignment and analyzed the data. YL and NW participated in the sample collection and clinical examination. JS and XD designed and supervised the study. LZ and YP wrote the manuscript. All authors read and approved the final manuscript.

\section{Funding}

This work was supported by the National Natural Science Foundation of China (No.81700837), the Natural Science Foundation of Hunan Province Project (No. 14JJ3041), and Department of Science and Technology, Hunan (No. 2015TP2007). The funders had no role in the study design, data collection and analysis, decision to publish or preparation of the manuscript.

\section{Availability of data and materials}

The datasets used and/or analyzed during the current study are available from the corresponding author on reasonable request.

\section{Ethics approval and consent to participate}

All procedures performed in studies involving human participants were in accordance with the ethical standards of the Second Xiangya Hospital Ethics
Committee and with the 1964 Helsinki Declaration and its later amendments or comparable ethical standards. Written consents have been obtained from all adult individuals included in the study. Written consent has been obtained from the mother of the individual under $18 \mathrm{yrs}$. in the study.

\section{Consent for publication}

Verbal consents for publication from the patients were obtained by phone, because when prepare the publication all the patients and their family members have left our hospital and returned home. Likewise, verbal consent for publication of the patient who is under $18 \mathrm{yrs}$. was obtained from her parent (her mother). The Second Xiangya Hospital Ethics Committee has approved the procedure performed in this study.

\section{Competing interests}

The authors declare that they have no competing interests.

Received: 8 October 2018 Accepted: 4 June 2019

Published online: 11 June 2019

\section{References}

1. Seifi M, Walter MA. Axenfeld-Rieger syndrome. Clin Genet. 2018;93(6):1123-30.

2. Chang TC, Summers CG, Schimmenti LA, Grajewski AL. Axenfeld-Rieger syndrome: new perspectives. Br J Ophthalmol. 2012;96(3):318-22.

3. Idrees F, Vaideanu D, Fraser SG, Sowden JC, Khaw PT. A review of anterior segment dysgeneses. Surv Ophthalmol. 2006;51(3):213-31.

4. Mammi I, De Giorgio P, Clementi M, Tenconi R. Cardiovascular anomaly in Rieger syndrome: heterogeneity or contiguity? Acta Ophthalmol Scand. 1998;76(4):509-12

5. Jena AK, Kharbanda OP. Axenfeld-Rieger syndrome: report on dental and craniofacial findings. The Journal of clinical pediatric dentistry. 2005;30(1):83-8.

6. Strungaru MH, Dinu I, Walter MA. Genotype-phenotype correlations in Axenfeld-Rieger malformation and glaucoma patients with FOXC1 and PITX2 mutations. Invest Ophthalmol Vis Sci. 2007;48(1):228-37.

7. Weisschuh N, De Baere E, Wissinger B, Tumer Z. Clinical utility gene card for: Axenfeld-Rieger syndrome. European journal of human genetics : EJHG. 2011;19(3): [Epub ahead of print].

8. Phillips JC, del Bono EA, Haines JL, Pralea AM, Cohen JS, Greff LJ, Wiggs J A second locus for Rieger syndrome maps to chromosome 13q14. Am J Hum Genet. 1996;59(3):613-9.

9. Werner W, Kraft S, Callen DF, Bartsch O, Hinkel GK. A small deletion of 16q23.1-->16q24.2 [del(16)(q23.1q24.2).Ish del(16)(q23.1q24.2)(D16S395+, D16S348-, P5432+)] in a boy with iris coloboma and minor anomalies. Am J Med Genet. 1997;70(4):371-6.

10. Yang Y, Muzny DM, Reid JG, Bainbridge MN, Willis A, Ward PA, Braxton A, Beuten J, Xia F, Niu Z, et al. Clinical whole-exome sequencing for the diagnosis of mendelian disorders. N Engl J Med. 2013;369(16):1502-11.

11. Do R, Kathiresan S, Abecasis GR. Exome sequencing and complex disease: practical aspects of rare variant association studies. Hum Mol Genet. 2012; 21(R1):R1-9.

12. Tumer Z, Bach-Holm D. Axenfeld-Rieger syndrome and spectrum of PITX2 and FOXC1 mutations. Eur J Hum Genet. 2009;17(12):1527-39.

13. Amendt BA, Semina EV, Alward WL. Rieger syndrome: a clinical, molecular, and biochemical analysis. Cell Mol Life Sci. 2000;57(11):1652-66.

14. Evans AL, Gage PJ. Expression of the homeobox gene Pitx2 in neural crest is required for optic stalk and ocular anterior segment development. Hum Mol Genet. 2005;14(22):3347-59.

15. Liu W, Selever J, Lu MF, Martin JF. Genetic dissection of Pitx2 in craniofacial development uncovers new functions in branchial arch morphogenesis, late aspects of tooth morphogenesis and cell migration. Development. 2003; 130(25):6375-85.

16. Tessari A, Pietrobon M, Notte A, Cifelli G, Gage PJ, Schneider MD, Lembo G, Campione M. Myocardial Pitx2 differentially regulates the left atrial identity and ventricular asymmetric remodeling programs. Circ Res. 2008;102(7):813-22.

17. Ai D, Wang J, Amen M, Lu MF, Amendt BA, Martin JF. Nuclear factor 1 and T-cell factor/LEF recognition elements regulate Pitx2 transcription in pituitary development. Mol Cell Biol. 2007;27(16):5765-75.

18. Doward W, Perveen R, Lloyd IC, Ridgway AE, Wilson L, Black GC. A mutation in the RIEG1 gene associated with Peters' anomaly. J Med Genet. 1999;36(2): 152-5. 
19. Alward WL, Semina EV, Kalenak JW, Heon E, Sheth BP, Stone EM, Murray JC. Autosomal dominant iris hypoplasia is caused by a mutation in the Rieger syndrome (RIEG/PITX2) gene. Am J Ophthalmol. 1998;125(1):98-100.

20. Kulak SC, Kozlowski K, Semina EV, Pearce WG, Walter MA. Mutation in the RIEG1 gene in patients with iridogoniodysgenesis syndrome. Hum Mol Genet. 1998;7(7):1113-7.

21. Footz T, Idrees F, Acharya M, Kozlowski K, Walter MA. Analysis of mutations of the PITX2 transcription factor found in patients with Axenfeld-Rieger syndrome. Invest Ophthalmol Vis Sci. 2009;50(6):2599-606.

22. Amen M, Liu X, Vadlamudi U, Elizondo G, Diamond E, Engelhardt JF, Amendt BA. PITX2 and beta-catenin interactions regulate Lef-1 isoform expression. Mol Cell Biol. 2007;27(21):7560-73.

\section{Publisher's Note}

Springer Nature remains neutral with regard to jurisdictional claims in published maps and institutional affiliations.

Ready to submit your research? Choose BMC and benefit from:

- fast, convenient online submission

- thorough peer review by experienced researchers in your field

- rapid publication on acceptance

- support for research data, including large and complex data types

- gold Open Access which fosters wider collaboration and increased citations

- maximum visibility for your research: over $100 \mathrm{M}$ website views per year

At BMC, research is always in progress.

Learn more biomedcentral.com/submissions 